\title{
Influence of Hybrid Fibres on Bond Strength of Concrete
}

\author{
Srinivasa Rao Naraganti \\ Department of Civil Engineering, \\ Sreenivasa Institute of Technology and Management Studies, Chittoor, 517127, India. \\ Corresponding author: srininara123@gmail.com \\ Rama Mohan Rao Pannem \\ Centre for Disater Mitigation and Management, \\ Vellore Institute of Technology, Vellore, 632014, India. \\ E-mail: rao_pannem@vit.ac.in \\ Jagadeesh Putta \\ School of Civil Engineering, \\ Vellore Institute of Technology, Vellore, 632014, India. \\ E-mail: p.jagadeesh@vit.ac.in
}

(Received August 1, 2019; Accepted December 10, 2019)

\begin{abstract}
Bond strength between embedded bar and concrete plays vital role in the design of various reinforced concrete structural elements. Use of metallic and synthetic fibres has been shown to be an effective method to enhance tensile strength, reduce shrinkage and improve durability properties of concrete. However, making of synthetic fibres will not only deplete the natural hydrocarbon resources, but also add greenhouse pollutants to the environment. Hence, sisal fibre was considered as a potential alternative to polypropylene fibre. An experimental study was conducted to evaluate the influence of sisal fibres as mono-fibre and in combination with steel as hybrid fibre on bond strength of concrete. The performance of steel polypropylene fibre reinforced concrete (SPFRC) is compared with that of steel sisal fibre reinforced concrete (SSiFRC). Bond strength was conducted onM30 grade concrete for curing periods of 7, 28 and 90 days. Fibre dosages of $0.50 \%, 1.00 \%, 1.25 \%$ and $1.50 \%$ by volume of concrete were used. Results indicated that increase in steel fibre dosage improved the bond strength slightly. However, increase in fibre dosage of either PP fibres or sisal fibres resulted decrease in bond strength. Furthermore, sisal fibre reinforced concrete (SiFRC) showed inferior performance in bond strength as compared to polypropylene fibre reinforced concrete (PFRC). A detailed statistical analysis revealed that although no strong correlation between the compressive strength and the bond strength was evident from the experimental study, means of bond strength of both the hybrid groups did not differ significantly. In addition, empirical equations were proposed to predict the bond strength of fibre reinforced concrete (FRC) based on compressive strength.
\end{abstract}

Keywords- Bond Strength; Fibre reinforced concrete; Steel fibres; Polypropylene fibres; Sisal fibres.

\section{Introduction}

The bond between steel and concrete is critical in designing reinforced concrete structures. Knowing the value of bond stress helps in computing additional length of a bar of specified diameter to be provided beyond a given critical section. However, no bond failure occurs if the actual extended length of a bar is equal or greater than the required development length. Bond forces along the bar are required to keep the steel and concrete deforming together. Forces that develop on the surface of bars to prevent significant slip from occurring at the concrete to steel interface are contributed to the bond.

Presence of steel fibres in concrete has been found to be effective in enhancing spectrum of 
International Journal of Mathematical, Engineering and Management Sciences

Vol. 5, No. 2, 353-362, 2020

https://doi.org/10.33889/IJMEMS.2020.5.2.029

engineering properties of concrete (Olivito and Zuccarello, 2010). Role of steel fibres in enhancing the bond strength of FRC has been reported by various authors. Addition of Steel fibres was found to be effective in improving the bond strength of concrete when used them as mono fibres as well (Yazici and Arel, 2013). Furthermore, it was reported that diameter of the bar does play a role in bond strength and larger diameter bars indicated higher bond strength as compared to rebars with smaller diameters at the same fibre fractions (Ezeldin and Balaguru, 1989). Steel fibre reinforced concrete (SFRC) exhibited higher resistance to pull-out load as compared to PFRC at the same fibre dosage. It was reported that more fibre dosage reduced the risk of splitting failure and this parameter was more important for concrete having high compressive strength (Garcia-Taengua et al., 2014). Moreover, it was concluded that higher fibre length of steel fibres leads to higher bond strength.

Potential use of polypropylene (PP) fibres in cement concrete has been advocated by various researchers across the globe (Rao et al., 2016). Addition of PP fibres strengthens and simultaneously can make an increase up to $90 \%$ in bondstrength of light-weight concrete and reinforcement (Hashemi and Mirzaei-Moghadam, 2014). On the other hand, reduction in the bond strength was observed when PP fibres were used in the concrete were made with quartz gravel and expanded clay (Balazs and Lubloy, 2012). Therefore, based on the published results, it is clear that the presence of PP fibres showed different results based on type of materials used in concrete. Though PP fibres showed superior performance in many studies, their continued usage adds up to greenhouse effect and depletes limited hydrocarbon resources. Hence, a locally available natural fibre (sisal fibre) was considered as an alternative to PP fibres.

Hybrid fibre reinforced concrete (HyFRC) gained momentum in recent past due to enhanced engineering properties and synergy among fibres. Amplified performance of hybrid fibres in improving various engineering properties has been widely reported (Naraganti et al., 2019; Sivakumar and Santhanam, 2007). Although wide literature is available on the influence of hybrid fibres on various engineering properties of HyFRC, very little findings have been reported on the effect of hybrid fibres on the bond strength of HyFRC. It was reported that neither MonoFRC nor HyFRC showed consistent performance in improving the bond strength of concrete for various fibre dosages and embedded bars (Ganesan et al., 2014). However, it was concluded that hybrid combination of steel and PP fibres showed superior performance in enhancing the bond strength of FRC. Additionally, it was reported that the anchorage length of the bars could be reduced by usage of hybrid fibre reinforced high performance concrete (HFRHPC).

Decrease in compressive strength of SFRC was observed when the dosage of steel fibre was increased from $1 \%$ to $2 \%$ (Olivito and Zuccarello, 2010). Hence, the maximum fibre dosage was limited to $1.50 \%$. Optimum steel fibre dosage for SPFRC is reported to be between $1-1.5 \%$ (Wang and Wang, 2013). Hence, the authors were curious to verify the engineering properties of FRC at a fibre dosage of $1.25 \%$. Thus, the fibre dosages of $0.50 \%, 1.00 \%, 1.25 \%$ and $1.50 \%$ by volume of concrete were considered in the study.

A few findings have been published on the effect of sisal fibre on the engineering properties of concrete. Moreover, no full-scale study, to the knowledge of the author, has been reported on understanding the role of sisal fibres as mono-fibre and in hybrid combination with steel fibres on bond strength of concrete. Hence, the experimental investigation was conducted to understand the effect of sisal fibres on the bond strength of FRC. 
International Journal of Mathematical, Engineering and Management Sciences

Vol. 5, No. 2, 353-362, 2020

https://doi.org/10.33889/IJMEMS.2020.5.2.029

\section{Material and Methods}

\subsection{Materials Used}

Ordinary portland cement confirming to Indian Standard (IS 8112, 2013) was used in the study. Naturally available river sand was used as fine aggregate and coarse aggregate was obtained from locally available Crushed stones. Tests were conducted in accordance with Indian Standard (IS $2386,2002)$ to ascertain the properties of aggregates. Specific gravity and water absorption of coarse and fine aggregate were 2.7 and $0.40 \%$, and 2.3 and $1.00 \%$ respectively. Mixing was done using clean water. Figure 1 shows the hooked end steel fibres, staple type PP fibres and locally available sisal fibres used in the study. $30 \mathrm{~mm}$ long steel fibres and $12 \mathrm{~mm}$ long PP and sisal fibres were used in the study. The steel fibres had specific gravity of 7.8, modulus of elasticity of $200 \mathrm{GPa}$ and tensile strength of $1050 \mathrm{MPa}$.

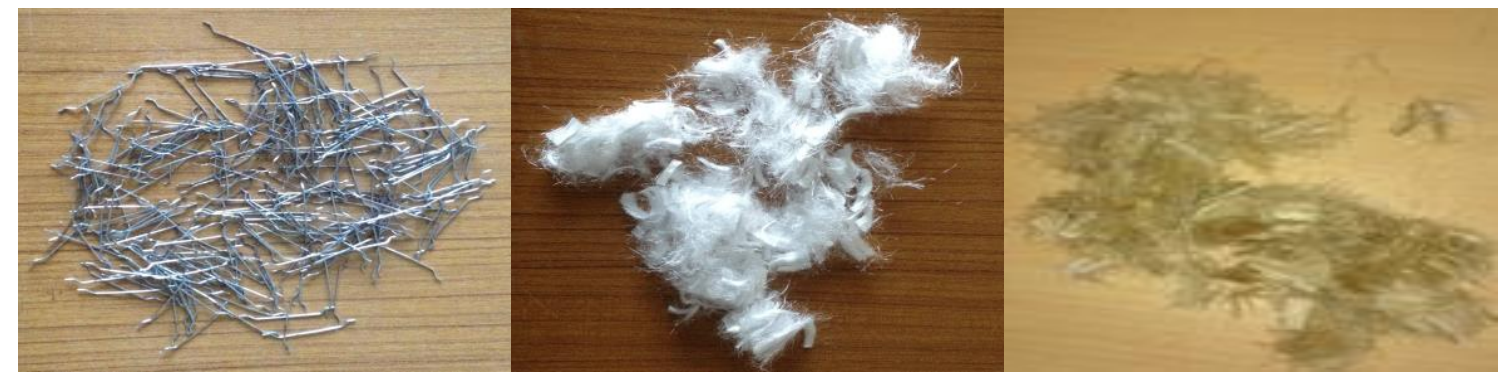

Steel fibres

PP fibres

Sisal fibres

Figure 1. Different fibres used in the experimental study

\subsection{Mixing Proportions}

Provisions made in Indian Standard (IS 10262, 2009; IS 456-2000, 2007) were followed to design the mix. W/c ratio of 0.50 and mix proportion of 1:1.74:3.33 were used in the study. Napthalene sulphonate based superplasticiser was used in the study and its quantity was fixed at $1 \%$ weight of cement. Table 1 shows the mix proportions used in the study. Hybrid combination of steel and PP fibres resulted in SPFRC and that of steel and sisal fibres resulted in SSiFRC. Three specimens were prepared for each mix and average results are reported.

Table 1. Mix proportions

\begin{tabular}{|c|c|c|c|c|c|c|c|c|c|c|}
\hline Mix & $\begin{array}{l}\text { Cement } \\
\left(\mathrm{kg} / \mathrm{m}^{3}\right)\end{array}$ & $\begin{array}{c}\text { Water } \\
\left(\mathrm{kg} / \mathrm{m}^{3}\right)\end{array}$ & $\begin{array}{c}\text { Fine } \\
\text { aggregate } \\
\left(\mathrm{kg} / \mathrm{m}^{3}\right)\end{array}$ & $\begin{array}{c}\text { Coarse } \\
\text { aggregate } \\
\left(\mathrm{kg} / \mathrm{m}^{3}\right)\end{array}$ & $\begin{array}{l}\text { Total } \\
\text { fibre } \\
\text { vol. } \\
(\%) \\
\end{array}$ & $\begin{array}{c}\text { Steel } \\
\text { fibre } \\
\text { vol. } \\
(\%) \\
\end{array}$ & $\begin{array}{c}\text { PP } \\
\text { fibre } \\
\text { vol. } \\
(\%)\end{array}$ & $\begin{array}{c}\text { Sisal } \\
\text { fibre } \\
\text { vol. } \\
(\%)\end{array}$ & $\begin{array}{l}\text { Proportions } \\
\text { of Steel + PP } \\
\text { fibre }\end{array}$ & $\begin{array}{c}\text { Proportions } \\
\text { of Steel }+ \\
\text { Sisal fibre }\end{array}$ \\
\hline PCC & 354.88 & 177.44 & 617.83 & 1183.35 & - & - & - & - & - & - \\
\hline S050 & 354.88 & 177.44 & 617.83 & 1183.35 & 0.50 & 0.50 & - & - & - & - \\
\hline $\mathrm{S} 100$ & 354.88 & 177.44 & 617.83 & 1183.35 & 1.00 & 1.00 & - & - & - & - \\
\hline S125 & 354.88 & 177.44 & 617.83 & 1183.35 & 1.25 & 1.25 & - & - & - & - \\
\hline S150 & 354.88 & 177.44 & 617.83 & 1183.35 & 1.50 & 1.50 & - & - & - & - \\
\hline P050 & 354.88 & 177.44 & 617.83 & 1183.35 & 0.50 & - & 0.50 & - & - & - \\
\hline P100 & 354.88 & 177.44 & 617.83 & 1183.35 & 1.00 & - & 1.00 & - & - & - \\
\hline P125 & 354.88 & 177.44 & 617.83 & 1183.35 & 1.25 & - & 1.25 & - & - & - \\
\hline P150 & 354.88 & 177.44 & 617.83 & 1183.35 & 1.50 & - & 1.50 & - & - & - \\
\hline $\mathrm{SiO50}$ & 354.88 & 177.44 & 617.83 & 1183.35 & 0.50 & - & - & 0.50 & - & - \\
\hline Si100 & 354.88 & 177.44 & 617.83 & 1183.35 & 1.00 & - & - & 1.00 & - & - \\
\hline
\end{tabular}


International Journal of Mathematical, Engineering and Management Sciences

Vol. 5, No. 2, 353-362, 2020

https://doi.org/10.33889/IJMEMS.2020.5.2.029

Table 1 continued...

\begin{tabular}{|lllllllllll|}
\hline Si125 & 354.88 & 177.44 & 617.83 & 1183.35 & 1.25 & - & - & 1.25 & - & - \\
\hline Si150 & 354.88 & 177.44 & 617.83 & 1183.35 & 1.50 & - & - & 1.50 & - & - \\
\hline SP050 & 354.88 & 177.44 & 617.83 & 1183.35 & 0.50 & - & - & - & $80+20$ & - \\
\hline SP100 & 354.88 & 177.44 & 617.83 & 1183.35 & 1.00 & - & - & - & $80+20$ & - \\
\hline SP125 & 354.88 & 177.44 & 617.83 & 1183.35 & 1.25 & - & - & - & $80+20$ & - \\
\hline SP150 & 354.88 & 177.44 & 617.83 & 1183.35 & 1.50 & - & - & - & $90+10$ & - \\
\hline SSi050 & 354.88 & 177.44 & 617.83 & 1183.35 & 0.50 & - & - & - & - & $80+20$ \\
\hline SSi100 & 354.88 & 177.44 & 617.83 & 1183.35 & 1.00 & - & - & - & - & $80+20$ \\
\hline SSi125 & 354.88 & 177.44 & 617.83 & 1183.35 & 1.25 & - & - & - & - & $90+10$ \\
\hline SSi150 & 354.88 & 177.44 & 617.83 & 1183.35 & 1.50 & - & - & - & - & $90+10$ \\
\hline
\end{tabular}

\section{Test Methodology}

\subsection{Bond Strength Test}

Concrete cubes with a vertically embedded reinforcing bar along the centroidal axis of the cube were used as specimens to ascertain the bond strength. In order to provide adequate gripping for the test, the length of the bar was kept at $300 \mathrm{~mm}$ from the top face of the cube. Cubes of size 150 $\mathrm{mm}$ with embedded bars of diameter $20 \mathrm{~mm}$ were used in the study. Helix reinforcement of mild steel bar with diameter $6 \mathrm{~mm}$ and pitch $25 \mathrm{~mm}$ was used. The helix reinforcement was kept inside the cube while casting the specimen. The purpose of the helical reinforcement was to make sure that the specimen would not fail due splitting failure before pull-out of the embedded bar occurs.

Guidelines as laid down in Indian Standard (IS 2770, 2007) were followed to prepare the specimens. Casting of the specimens was done using steel moulds. The moulds were filled with concrete in three layers and each layer was vibrated for 15 seconds to ensure proper compaction after placing it on the vibrating table. Leveling of surface of the specimen was done for smooth surface. Specimens were prepared for fibre dosages of $0.50 \%, 1.00 \%, 1.25 \%$ and $1.50 \%$ of volume of concrete with steel proportion varying from $90 \%$ to $60 \%$ and PP / sisal proportions varying from $10 \%$ to $40 \%$ as mentioned above. Loss of moisture was prevented by covering the specimens with wet gunny bags. Specimens were removed from the moulds after 24 hours of casting and kept in clean water for 7, 28 and 90 days. Three specimens were prepared for each mix and average bond strength values are reported.

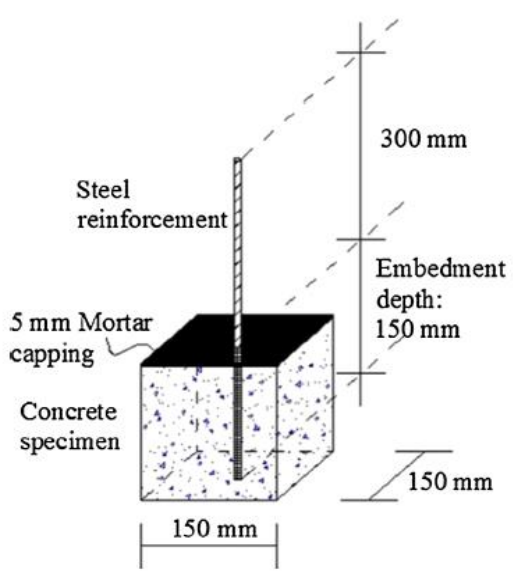

Figure 2. Schematic diagram of the Specimen 
Schematic diagram of the specimen prepared for conducting the bond strength is shown in Figure 2. The test was conducted as per Indian Standard (IS 2770, 2007) Part1 using a $400 \mathrm{kN}$ capacity Universal Testing Machine (UTM). The load was applied at a rate not greater than $22.5 \mathrm{kN} / \mathrm{min}$. After the specified curing periods, the test specimen was mounted on the UTM in such a way that the bar is axially pulled from the specimen. The test was conducted until either pull-out of the bar or yielding of the steel bar occurred.

Bond Strength $=\frac{P}{\pi D L}$

where, $P=$ Ultimate Load in ' $\mathrm{N}$ '

$D=$ Diameter of the bar in ' $m$ '

$L=$ Length of the bar inserted in ' $\mathrm{mm}$ '

The bond stress between the surrounding concrete and the reinforcing bar was calculated using (1). Uniform distribution of bond stress was assumed in computing the average bond stress.

\subsection{Statistical Analysis}

A liner regression analysis between bond strength of SPFRC and SSiFRC was conducted to understand the synergetic effect between steel and PP/sisal fibres. Statistical analysis, namely Ttest, was also performed to understand the difference in means for the bond strength data obtained between SPFRC and SSIFRC. This test could help ascertain if the mean values of bond strength from both the groups are significantly different.

\section{Results and Discussion}

\subsection{Bond Strength}

Effect of addition of steel and PP fibres separately and in combination on bond strength of FRC was evaluated for curing periods 7, 28 and 90 days. The response of SFRC, PFRC and SiFRC to bond strength for curing period of 28 days in the form of graphical representation is shown in Figure 3. Presence of steel fibres was found to be beneficial to bond strength of concrete. A fibre dosage of $0.50 \%, 1.00 \%, 1.25 \%$ and $1.50 \%$ resulted increase of $2.04 \%, 5.67 \%, 7.19 \%$ and $10.69 \%$ in bond strength. Moreover, bond strength improved with the age for all fibre dosages. Greater pull-out resistance of hooked-end steel fibres and increased grip between steel fibres and embedded bar could be the main reasons for enhanced bond strength of SFRC. The test results for SFRC are inline with the findings reported by various authors (Alanki et al., 2013; Guneyisi et al., 2013; Garcia-Taengua et al., 2016).

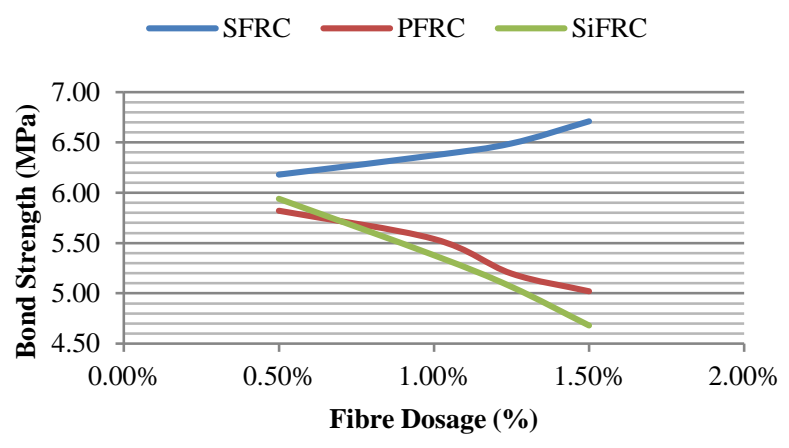

Figure 3. Performance of mono-FRC at 28 days age 
International Journal of Mathematical, Engineering and Management Sciences

Vol. 5, No. 2, 353-362, 2020

https://doi.org/10.33889/IJMEMS.2020.5.2.029

Addition of any quantity of PP fibres to the control mix showed damaging effect on the bond strength of FRC. Increase in fibre dosage of PP fibres resulted declining trend in bond strength of the concrete for all ages. Maximum drop of $17.68 \%$ in bond strength was observed for a fibre dosage of $1.50 \%$. The declining trend in bond strength of PFRC was mainly due to smooth surface of the PP fibres (Joseph et al., 1996) and thereby offering less friction between the embedded bar and the PP fibres. More fibre volume means more number of PP strands available for a given volume of concrete due to less specific gravity and thereby less friction between the embedded bar and surrounded PP fibres. Hence, it makes easier to pull-out the embedded bar when fibre dosage of PP fibres is increased.

Presence of sisal fibres showed similar effect as that of PP fibres as shown in Figure 3. However, sisal fibres showed more adverse effect on bond strength as compared to the performance of PP fibres. Decrease in bond strength by $1.94 \%, 10.85 \%, 14.04 \%$ and $23.80 \%$ was observed for fibre dosages of $0.50 \%, 1.00 \%, 1.25 \%$ and $1.50 \%$. Curing SiFRC for 90 days did not show any abnormal trend of bond strength. It indicates that sisal fibres did not undergo any appreciable biodegradation under constant contact with water during the process of curing. Declining trend of SiFRC on bond strength is mainly due to porous nature of the sisal fibre and offering less frictional resistance to embedded bar when it was pull-out.

Although PFRC and SiFRC showed declining trend in bond strength with increasein fibre dosage, SFRC offered more resistance to pull-out strength of embedded bar. Due to porous nature of sisal fibres and smooth surface of PP fibres, they could not add much to the improvement of bond strength with increase in fibre dosage. For example, Figure 3 shows the performance of SFRC and PFRC at various fibre dosages for the curing period of 28 days. It can be seen that SFRC outperformed as compared to PFRC and SiFRC. Nonetheless, PFRC and SiFRC showed similar performance. However, more variation in the performance of PFRC and SiFRC was observed at a volume fraction of $1.50 \%$.

SPFRC demonstrated superior performance at different levels for various relative proportions of steel and PP fibres as shown in Figure 4. However, synergy between the fibres was observed at all total volume fractions. Mixes SP050, SP100, SP125 and SP150 resulted maximum increase of $2.89 \%, 8.80 \%, 11.03 \%$ and $11.66 \%$ respectively at a given total volume fraction. Through it was reported that maximum bond strength was observed for the combination of $1 \%$ volume fraction of steel fibres and $0.10 \%$ of volume fractions of PP fibres, the maximum bond strength was found at $1.35 \%$ volume fraction of steel fibres and $0.15 \%$ of PP fibres.

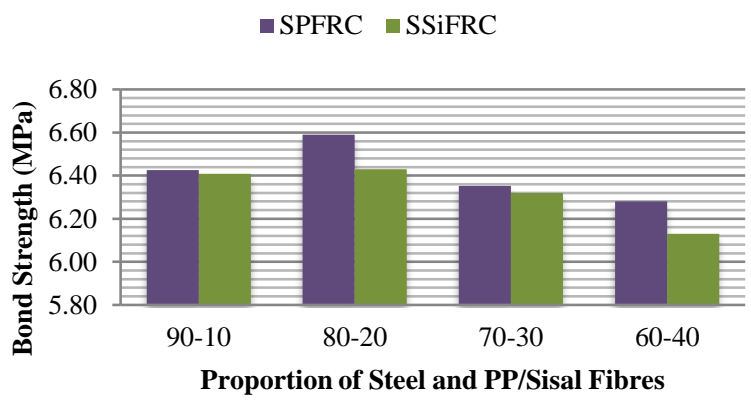

Figure 4. Performance of HyFRC at 28 days age 
The experimental investigation shows the positive role played by steel and PP hybrid combination in enhancing bond strength of FRC. Although, addition of only PP fibres resulted in adverse effect, presence of hybrid combination of steel and PP fibres enhanced the bond strength as much as $11.66 \%$.

On contrary to performance of SPFRC, addition of steel and sisal hybrid combination showed improvement in bond strength only for the total fibre dosages $0.50 \%$ and $1.00 \%$. Mixes SSi050 and SSi100 showed increase of $3.07 \%$ and $6.36 \%$ in bond strength respectively. It indicates that steel and sisal fibres gel-well in offering resistance to pull-out failure of embedded bar at low volume fraction of $0.50 \%$ and $1.00 \%$. Further increase in proportion of sisal fibres showed detrimental effect on the bond strength. More number of sisal fibres would be available for a given proportion of total fibre volume and thereby the nature of sisal fibres causes decreasing trend on bond strength.

Although synergy between steel and PP fibres was observed at all total volume fractions, steel and sisal fibres showed such effect only for the volume fractions of $0.50 \%$ and $1.00 \%$. However, interestingly, both SPFRC and SSiFRC showed improved performance in bond strength as compared to Mono-FRC at the same relative proportions of steel and PP / sisal fibres. For instance, at volume fraction the mix SP0501 and SSi0501 showed improved performance as compared to SFRC. Moreover, similar observation was made at the total volume fraction of $1.00 \%$. Despite PP and sisal fibres alone showing similar performance at higher fibre dosage of $1.25 \%$ and $1.50 \%$, their individual combination with steel fibres showed contradicting performance. Due to presence of helix provided inside the specimen, no tensile cracks in the specimen were observed during the testing. A failed specimen in bond strength is shown in Figure 5. It can be seen from the image that the embedded bar was pulled-out and no damage to the surface of the specimen was evident.

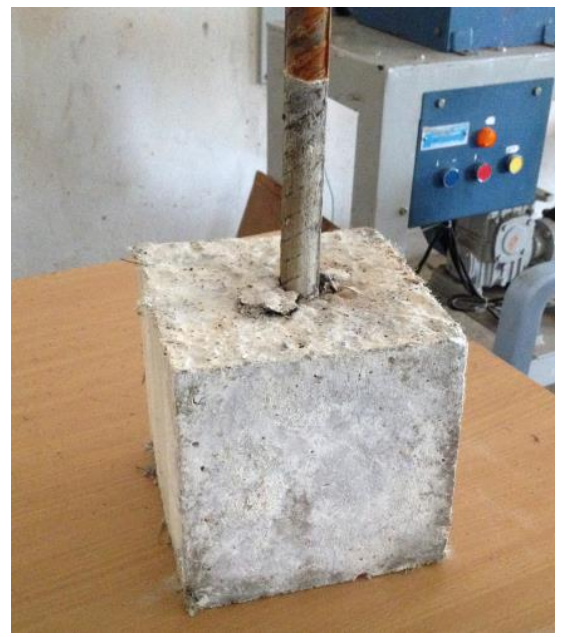

Figure 5. Test specimen after pull-out test 
International Journal of Mathematical, Engineering and Management Sciences

Vol. 5, No. 2, 353-362, 2020

https://doi.org/10.33889/IJMEMS.2020.5.2.029

\subsection{Statistical Analysis}

A linear regression analysis performed between the SPFRC and SSiFRC in enhancing bond strength resulted R-squared value of 0.92 . Hence, it can be inferred that the synergy between the steel and PP fibres is different from that between steel and sisal fibres even in improving the bond strength. Additionally, the linear regression analysis indicates poor correlation between both the parameters. The derived relation between the bond strength $\left(f_{b s}\right)(\mathrm{MPa})$ and compressive strength $\left(f_{c s}\right)(\mathrm{MPa})$ (Naraganti et al., 2019) for SPFRC and SSiFRC are shown in (2) and (3) respectively. Good agreement between the experimental results and values obtained through the equations was observed.

$f_{b s}=0.0707 f_{c S}^{1.1828}$

$f_{b s}=0.1068 f_{c S}^{1.0672}$

Hence, it is safe to conclude from the linear regression analysis that compressive strength and bond strength are not correlated for HyFRC. Although fibres in isolation or in hybrid combination with steel fibres improved compressive and bond strength marginally, the highest growth was observed at different relative proportions for both strength parameters.

Result of t-test is shown in Figure 6. It can be seen from the test result that ' $t$ ' value (1.1034) is less than critical value (1.98). Hence, it is safe to state that the means of bond strength of SPFRC and SSiFRC are not significantly different. Although the synergic effect between the steel and sisal is not on par with that of steel and PP fibres, the mean bond strength for the spectrum of fibre dosages and combinations did not differ significantly.

\begin{tabular}{|c|ccc|}
\hline & SPFRC & SSiFRC \\
\hline Mean & 5.9819 & & 5.868 \\
Variance & 0.3988 & & 0.3992 \\
Stand. Dev. & 0.6315 & & 0.6318 \\
$\mathrm{n}$ & 75 & & 75 \\
$\mathrm{t}$ & & 1.1034 & \\
degrees of freedom & & 148 & \\
critical value & & 1.98 \\
\end{tabular}

Figure 6. T-test results

From the experimental study it can be noticed that although sisal as mono fibre showed detrimental effect on the bond strength of concrete, its hybrid combination with steel that enhanced bond strength. Hence, sisal fibre could be used in hybrid combination with steel fibre for enhancing the bond strength. This would also help in reducing the development length of reinforced concrete structures and thereby contribute to building economical reinforced structures. 
International Journal of Mathematical, Engineering and Management Sciences

Vol. 5, No. 2, 353-362, 2020

https://doi.org/10.33889/IJMEMS.2020.5.2.029

\section{Conclusions}

The performance of sisal fibre as lone fibre or in combination with steel fibre has been ascertained in improving the bond strength. In addition, the performance of sisal as mono fibre was compared with that of steel or PP fibres. Furthermore, the performance of sisal fibre in hybrid combination with steel fibre has been ascertained and compared it with that of SPFRC. The following conclusions are drawn from the experimental studies.

- Steel fibres alone improved the bond strength to the extent of $10.69 \%$. However, PP or Sisal fibres improved the bond strength marginally only at lower fibre dosages. Increase in the dosage of PP or sisal fibres alone had detrimental effect on the bond strength.

- Although synergy between steel and PP fibres was observed in enhancing bond strength, similar synergy between steel and sisal fibres was not detected. Maximum increase in bond strength was $11.66 \%$ and $9.78 \%$ for the mix SP150 and SSi150 respectively. Moreover, unlike for conventional concrete, weak correlation was found between the compressive strength and the bond strength of the FRC.

- Though bond and compressive strength were evaluated for the ages 7, 28 and 90 days, no abnormal variations in strength after 28 days were observed. Moreover, more gain in strength with age was also not observed at 90 days as no extraneous pozzolanic materials such as fly ash were added.

- Statistical analysis revealed that means of bond strength of SPFRC and SSiFRC are not significantly different.

- Mathematical equation has been proposed to predict the bond strength of SPFRC and SSiFRC based on compressive strength.

\section{Conflict of Interest}

The author confirms that there is no conflict of interest to declare for this publication.

\section{Acknowledgement}

The author acknowledges and expresses the gratitude to the reviewer's constructive comments and valuable suggestion for enhancing the quality of the manuscript.

\section{References}

Alanki, A.A., Wegian, F.M., Abdalghaffar, M.A., Alotaibi, F.A., Al-Temeemi, A.A., \& Alkhamis, M.T. (2013). Behavior of high-performance pull-out bond strength offibers reinforced concrete structures. Jordan Journal of Civil Engineering, 7(1), 93-100.

Balázs, G.L., \& Lublóy, E. (2012). Reinforced concrete structures in and after fire. Concrete Structures, 13, $72-80$.

Ezeldin, A., \& Balaguru, P. (1989). Bond behavior of normal and high-strength fiber reinforced concrete. ACI Materials Journal, 86(5), 515-524.

Ganesan, N., Indira, P.V., \& Sabeena, M.V. (2014). Bond stress slip response of bars embedded in hybrid fibre reinforced high performance concrete. Construction and Building Materials, 50, 108-115. 
International Journal of Mathematical, Engineering and Management Sciences

Vol. 5, No. 2, 353-362, 2020

https://doi.org/10.33889/IJMEMS.2020.5.2.029

Garcia-Taengua, E., Mart-Vargas, J.R., \& Serna, P. (2014). Splitting of concrete cover in steel fiber reinforced concrete: semi-empirical modeling and minimum confinement requirements. Construction and Building Materials, 66, 743-751.

Garcia-Taengua, E., Mart-Vargas, J.R., \& Serna, P. (2016). Bond of reinforcing bars to steel fiber reinforced concrete. Construction and Building Materials, 105, 275-284.

Güneyisi, E., Gesoğlu, M., \& İpek, S. (2013). Effect of steel fiber addition and aspect ratio on bond strength of cold-bonded fly ash lightweight aggregate concretes. Construction and Building Materials, 47, 358-365.

Hashemi, S.H., \& Mirzaei-Moghadam, I. (2014). Influence of nano-silica and polypropylene fibers on bond strength of reinforcement and structural lightweight concrete. IJE Transactions B: Applications, 27(2), 261-268.

Indian standard 10262 (2009). Concrete mix proportioning guidelines. Bureau of Indian Standards, New Delhi.

Indian Standard 2386 - Part1 (2002). Method of test for aggregates for concrete. Bureau of Indian Standards, New Delhi.

Indian Standard 2770-Part1 (2007). Methods of testing bond in reinforced concrete. Bureau of Indian Standards, New Delhi.

Indian Standard 456:2000 (2007). Plain and reinforced concrete - code of practice. Bureau of Indian Standards, New Delhi.

Indian Standard 516 (2006). Method of tests for strength of concrete. Bureau of Indian Standards, New Delhi.

Indian Standard 8112 (2013). Ordinary portland cement, 43 grade specification. Bureau of Indian Standards, New Delhi.

Joseph, K., Varghese, S., Kalaprasad, G., Thomas, S., Prasannakumari, L., Koshy, P., \& Pavithran, C. (1996). Influence of interfacial adhesion on the mechanical properties and fracture behaviour of short sisal fibre reinforced polymer composites. European Polymer Journal, 32(10), 1243-1250.

Naraganti, S.R., Pannem, R.M.R., \& Putta, J. (2019). Impact resistance of hybrid fibre reinforced concrete containing sisal fibres. Ain Shams Engineering Journal, 10(2), 297-305.

Olivito, R.S., \& Zuccarello, F.A. (2010). An experimental study on the tensile strength of steel fiber reinforced concrete. Composites Part B: Engineering, 41(3), 246-255.

Rao, N.S., Rao, P.R.M., \& Jagadeesh, P. (2016). Compressive strength of mono -fibre reinforced concrete containing polypropylene and sisal fibres. International Journal of Earth Sciences and Engineering, 9(3), 969-972.

Sivakumar, A., \& Santhanam, M. (2007). Mechanical properties of high strength concrete reinforced with metallic and non-metallic fibres. Cement and Concrete Composites, 29(8), 603-608.

Wang, H.T., \& Wang, L.C. (2013). Experimental study on static and dynamic mechanical properties of steel fiber reinforced lightweight aggregate concrete. Construction and Building Materials, 38,11461151.

Yazici, S., \& Arel, H.S. (2013). The effect of steel fiber on the bond between concrete and deformed steel bar in SFRCs. Construction and Building Materials, 40, 299-305.

Original content of this work is copyright () International Journal of Mathematical, Engineering and Management Sciences. Uses under the Creative Commons Attribution 4.0 International (CC BY 4.0) license at https://creativecommons.org/licenses/by/4.0/ 